\title{
COMPARISON OF SALBUTAMOL ALONE AND SALBUTAMOL IN COMBINATION WITH IPRATROPIUM BROMIDE IN TREATMENT OF ACUTE ASTHMA IN CHILDREN.
}

\footnotetext{
1. MBBS, FCPS (Peads Medicine) Senior Registrar Pediatric Medicine Nishtar Hospital Multan.

2. MBBS, FCPS (Peads Medicin) Associate Professor Pediatric Medicine Pediatrition, Laeeq Rafiq Hospital, Multan.

3. MBBS

Pediatrician Pediatric Medicine Nishtar Medical College \& Hospital Multan.

4. MBBS, MPH

PGT MS Peads Surgery

Nishtar Medical College \& Hospital, Multan.
}

Correspondence Address:

Dr. Saima Jabeen Joiya Department of Pediatric Medicine Nishtar Hospital Multan. zahidahmad78@gmail.com

Article received on: 04/02/2019

Accepted for publication: 07/05/2019

\section{Saima Jabeen Joiya1, Farhan ul Haq², Muhammad Azam Khan ${ }^{3}$, Zahid Ahmad}

ABSTRACT... Objectives: Asthma affects about $15 \%$ of children while it is one of the commonest reason for admissions in pediatric emergencies and wards. We aimed this study to determine outcome of Salbutamol alone and salbutamol in combination with Ipratropium Bromide in acute asthma in children. Study Design: Randomized Controlled trial (RCT). Setting: Unit-II Department of Pediatric Medicine, Nishtar Medical College and Hospital, Multan. Period: $20^{\text {th }}$ Nov 2017 to $30^{\text {th }}$ June 2018. Material \& Methods: The study consisted of 104 children, with 52 children each in Group 'A' and 'B' who were subjected to salbutamol alone and salbutamol in combination with Ipratropium bromide respectively. In both groups oxygen was administered via nasal prongs at a flow rate of $3 \mathrm{~L} /$ minute. These children was monitored at 30 minutes interval for 2 hours (least value out of these 4 values was taken). Both groups were compared for outcome in terms of mean heart rate, respiratory rate, accessory muscle score, peak expiratory flow rate (PERF) percentage and $\mathrm{SPO}_{2}$. Results: Of these 104 study cases, 61 $(58.7 \%)$ were boys while $43(41.3 \%)$ were girls. Mean age of our study cases was noted to be $9.92 \pm 3.01$ years. Mild level of asthma severity was noted in $35(33.7 \%)$ and moderate severity in $69(66.3 \%)$. Mean heart rate in group A was noted to be $119.40 \pm 12.22$ and in group was $119.29 \pm 8.51$ beats per minute. $(p=0.956)$. Mean respiratory rate in group $A$ was $29.98 \pm$ 4.00 while in group $B$ was $27.88 \pm 3.85(p=0.000)$. Mean accessory muscle score in group A was $0.537 \pm 0.336$ while in group $B$ was $0.130 \pm 0.030(p=0.000)$. Mean PEFR percentage in group $A$ was $68.69 \pm 18.64$ while in group $B$ was $87.12 \pm 17.10(p=0.000)$. Mean $\mathrm{SPO}_{2}$ in group $A$ was $96.15 \pm 1.05$ while it was $95.94 \pm 1.29(p=0.362)$. Conclusion: Our study results have shown that nebulization of salbutamol in combination with Ipratropium Bromide is more effective in the management of children with acute asthma. It was safe, effective and reliable as there was no adverse side effect noted in our study. We recommend the use of this combination nebulization therapy in children with acute asthma.

Key words: $\quad$ Acute Asthma, Ipratropium Bromide, PERF, Salbutamol, $\mathrm{SPO}_{2}$.

Article Citation: Joiya SJ, Farhan ul Haq, Khan MA, Ahmad Z. Comparison of salbutamol alone and salbutamol in combination with ipratropium bromide in acute asthma in treatment of children. Professional Med J 2020; 27(6):1103-1107. DOI: 10.29309/TPMJ/2020.27.06.3218

\section{INTRODUCTION}

Asthma affects more than 300 million people around the world while a $50 \%$ increase is reported every decade. ${ }^{1-3}$ Asthma affects about $15 \%$ of children while it is one of the commonest reason for admissions in pediatric emergencies and wards. Poor asthma control is observed in $26-45 \% .^{4}$

In South Asia ${ }^{2}$, the prevalence of asthma is noted to be around $30 \%$. The International Study of Asthma and Allergies in Childhood (ISAAC) study reported $8 \%$ prevalence of asthma in the paediatric population of Pakistan but these figures are considered to be lower while masking the original numbers. ${ }^{5}$ Young children pose major challenge in terms of asthma diagnosis as conventional pulmonary function testing is not available for them. Asthma management in terms of drugs are same for both adults and children but difference lies regarding symptoms, presentation and most effective management strategy in these two different age groups. ${ }^{4,5}$ Anticholinergics such as Ipratropium Bromide given with $\beta 2$-agonists like Salbutamol have been found valuable in minimizing hospitalization amongst children 
presenting with moderate to severe asthma exacerbation. ${ }^{6-8}$

A study conducted by Chakraborti et al reported PEFR percentage $82.32 \pm 25.93$ in children nebulized with salbutamol with Ipratropium bromide while it was $69.53 \pm 19.87$ with salbutamol alone. ${ }^{9} \mathrm{In}$ this study heart rate/ $\mathrm{min}$ was $119.43 \pm 17.09$ versus $115.3 \pm 18.7$, respiratory rate/min27.9 \pm 4.67 versus $28.97 \pm 5.84$, accessory muscle score was $0.17 \pm 0.46$ versus $0.43 \pm 0.82$ and $\mathrm{SPO}_{2}$ was $96.97 \pm 2.08$ versus $96.4 \pm 1.69$ in Salbutamol with ipratropium group and Salbutamol alone respectively. ${ }^{9}$

The findings of this study will be useful for the clinicians who are treating asthma for better treatment option to be adopted as there is no such study done in children at national level. The results will also be helpful for other researchers to design more advanced studies in this area which will lead to the proper management of asthmatic exacerbations. The study results will generate useful database of our population which was compared with those of from other countries.

\section{MATERIAL \& METHODS}

This study was conducted from 20 Nov 2015 to 30 Jun 2016 at the Unit-II Department of Pediatric Medicine, Nishtar Medical College and Hospital, Multan, after approval of Hospital Ethical Committee. Here 104 children with diagnosis of acute asthma were included using non-probability consecutive sampling technique. Sample size was calculated using WHO sample size calculator taking level of significance 5\% and power of test $80 \%$ (using statistics for mean PEFR in group A as $82.32 \pm 25.93$ and group $B$ as $69.53 \pm 19.87) .^{9}$ Inclusion criteria were all children aged 5-15 years of both gender having acute asthma from less than 1 month. Children with severe exacerbation; coexisting cardiac or renal disease, known intolerance to salbutamol or ipratropium bromide, already diagnosed with congenital or acquired immunodeficiency and diagnosed Tb were excluded.

Informed consent was taken from the parents or guardians of each child. Baseline information like mean heart rate, mean respiratory rate, mean oxygen saturation, mean accessory muscle score and mean PEFR were taken. These study cases were randomly divided into 2 groups by draws methods (Group A and Group B). Group A, each child was nebulized with salbutamol sulfate $0.03 \mathrm{ml} / \mathrm{kg} /$ dose of $0.5 \%$ respiratory solution while group $B$ was nebulized with additional $1 \mathrm{ml}$ of $0.025 \%$ solution of ipratropium bromide (in addition to salbutamol as in group A). In both groups oxygen was administered via nasal prongs at a flow rate of $3 \mathrm{~L} /$ minute. These children was monitored at 30 minutes interval for 2 hours (least value out of these 4 values was taken). All these procedures were performed by a senior consultant having 5 years post fellowship experience. All the findings were recorded in the study proforma.

All the data was entered and analyzed by SPSS18. Descriptive statistics was applied to calculate mean and standard deviation for quantitative variables. Frequencies and percentage were calculated for the categorical variables. Student's $t$ test was applied to compare the outcomes in both groups. $P$ value equal or less than 0.05 was considered as significant.

\section{RESULTS}

Our study included a total of 104 patients with acute asthma who met inclusion criteria of our study. Of these 104 study cases, 61 (58.7\%) were boys while 43 (41.3\%) were girls. Mean age of our study cases was noted to be $9.92 \pm 3.01$ years (range; $6-15$ years). Majority of our study cases i.e. 59 (56.7\%) were aged $5-10$ years of age. Mild level of asthma severity was noted in 35 $(33.7 \%)$ and moderate severity was noted in 69 (66.3\%). (Table-I).

Mean heart rate was noted to be $119.35 \pm$ 10.48 beats per minute. Mean respiratory rate was $28.93 \pm 4.05$ per minute. Mean accessory muscle score was noted to be $0.333 \pm 0.19$ while mean PEFR percentage was noted to be $77.90 \pm$ 20.06 and mean oxygen saturation was $96.05 \pm$ 1.17. Mean heart rate in group $A$ was noted to be $119.40 \pm 12.22$ and in group was $119.29 \pm 8.51$ beats per minute. $(p=0.956)$. Mean respiratory 
rate in group A was $29.98 \pm 4.00$ while in group $B$ was $27.88 \pm 3.85(p=0.000)$. Mean accessory muscle score in group A was $0.537 \pm 0.336$ while in group $B$ was $0.130 \pm 0.030(p=0.000)$. Mean PEFR percentage in group A was $68.69 \pm 18.64$ while in group $B$ was $87.12 \pm 17.10(p=0.000)$. Mean $\mathrm{SPO}_{2}$ in group $\mathrm{A}$ was $96.15 \pm 1.05$ while it was $95.94 \pm 1.29(p=0.362)$. (Table-II)

\section{DISCUSSION}

Asthma is known be a common problem among children while it is estimated to have a lifetime prevalence of $11-16 \% .^{10}$ Potentially, severe episodes of asthma are life threatening. Timely assessment and treatment bring favorable outcomes. ${ }^{10}$

Our study included a total of 104 patients with acute asthma who met inclusion criteria of our study. Of these 104 study cases, 61 (58.7\%) were boys while 43 (41.3\%) were girls. Al - Abdullah et $\mathrm{al}^{11}$ from Iraq also reported male gender predominance in children with acute asthma to be $58.2 \%$ which is similar to our study results. A study conducted by Memon et $\mathrm{al}^{12}$ from Karachi has reported $56 \%$ male gender predominance which is similar to our study results. Chakaraborti et $\mathrm{al}^{9}$ reported $60 \%$ male gender preponderance which is similar to that of our study results.

\begin{tabular}{|c|c|c|c|}
\hline Variable & Group A & Group B & Total \\
\hline \multicolumn{4}{|l|}{ Age Groups } \\
\hline $5-10$ years & $29(55.8 \%)$ & $30(57.7 \%)$ & Mean $\pm S D=9.92 \pm 3.01$ years \\
\hline $10-15$ years & $23(44.2 \%)$ & $22(42.3 \%)$ & \\
\hline \multicolumn{4}{|l|}{ Gender } \\
\hline Male & $28(53.8 \%)$ & $33(63.5 \%)$ & $61(58.70 \%)$ \\
\hline Female & $24(46.2 \%)$ & $19(36.5 \%)$ & $43(41.3 \%)$ \\
\hline \multicolumn{4}{|l|}{ Disease severity } \\
\hline Mild & $18(34.6 \%)$ & $17(32.7 \%)$ & $35(33.7 \%)$ \\
\hline Moderate & $34(65.4 \%)$ & $14(40 \%)$ & $69(66.3 \%)$ \\
\hline \multicolumn{4}{|l|}{ Steroid Therapy } \\
\hline Budesonid & $34(65.4 \%)$ & $35(67.3 \%)$ & $69(66.3 \%)$ \\
\hline Fluticasone & $18(34.6 \%)$ & $17(32.7 \%)$ & $35(33.7 \%)$ \\
\hline \multicolumn{4}{|l|}{ Disease duration } \\
\hline Less than 15 days & $21(40.4 \%)$ & $20(38.5 \%)$ & $41(39.4 \%)$ \\
\hline More than 15 days & $31(59.6 \%)$ & $32(61.5 \%)$ & $63(60.6 \%)$ \\
\hline \multicolumn{4}{|l|}{ URTI } \\
\hline Yes & $26(50 \%)$ & $31(59.6 \%)$ & $57(54.8 \%)$ \\
\hline No & $26(50 \%)$ & $21(40.4 \%)$ & $47(45.2 \%)$ \\
\hline
\end{tabular}

Table-I. Characteristic of study population $(n=104)$

\begin{tabular}{|l|c|c|c|}
\hline \multirow{2}{*}{\multicolumn{1}{|c|}{ Outcome }} & \multicolumn{2}{c|}{ Groups } \\
\cline { 2 - 4 } & Mroup A & Group B & P-Value \\
\cline { 2 - 4 } & Mean (SD) & $119.29 \pm 8.51$ & 0.956 \\
\hline Heart rate/min & $119.40 \pm 12.22$ & $27.88 \pm 3.85$ & 0.008 \\
\hline Accessory muscle score & $29.98 \pm 4.00$ & $0.130 \pm 0.030$ & 0.001 \\
\hline PEFR \% & $0.537 \pm 0.336$ & $87.12 \pm 17.10$ & 0.001 \\
\hline SPO $_{2}$ & $68.69 \pm 18.64$ & $95.94 \pm 1.29$ & 0.362 \\
\hline
\end{tabular}

Table-II. Comparison of outcome of therapy in both groups: 
Mean age of our study cases was noted to be $9.92 \pm 3.01$ years (range; $6-15$ years). Majority of our study cases i.e. 59 (56.7\%) were aged 5 - 10 years of age. $\mathrm{Al}-\mathrm{Abdullah}$ et $\mathrm{al}^{13}$ from Iraq also reported similar results. A study conducted by Memon et $\mathrm{al}^{12}$ from Karachi has reported 9.2 \pm 2.9 years mean age of the patients with acute asthma. Chakaraborti et $\mathrm{al}^{9}$ reported from India mean age of these patients with acute asthma to be $106 \pm 25$ months which is similar to our study.

Mild level of asthma severity was noted in 35 (33.7\%) and moderate severity was noted in 69 $(66.3 \%)$ of our study cases. A study conducted by Fayaz et al $^{13}$ from UK also reported moderate level of severity of asthma predominated which is in compliance with our study results. Chakaraborti et $\mathrm{al}^{9}$ also reported similar results from India showing mild severity being more common than mild level of severity.

Upper respiratory tract infection (URTI) was present in $54.8 \%$ of our study cases. Chakaraborti et $\mathrm{al}^{9}$ from India reported $50 \%$ URTI in patients with acute asthma. These findings of Chakaraborti et al ${ }^{9}$ are similar to that of our study results.

In our study mean heart rate was noted to be 119.35 \pm 10.48 beats per minute. Mean respiratory rate was $28.93 \pm 4.05$ per minute. Mean accessory muscle score was noted to be $0.333 \pm 0.19$ while mean PEFR percentage was noted to be $77.90 \pm$ 20.06 and mean oxygen saturation was $96.05 \pm$ 1.17. Mean heart rate in group $A$ was noted to be $119.40 \pm 12.22$ and in group was $119.29 \pm 8.51$ beats per minute. $(p=0.956)$. Mean respiratory rate in group $A$ was $29.98 \pm 4.00$ while in group $B$ was $27.88 \pm 3.85(p=0.000)$. Mean accessory muscle score in group A was $0.537 \pm 0.336$ while in group $B$ was $0.130 \pm 0.030(p=0.000)$. Mean PEFR percentage in group A was $68.69 \pm$ 18.64 while in group $B$ was $87.12 \pm 17.10(p=$ 0.000). Mean $\mathrm{SPO}_{2}$ in group $A$ was $96.15 \pm 1.05$ while it was $95.94 \pm 1.29(p=0.362)$. A study conducted by Chakraborti et al reported PEFR percentage $82.32 \pm 25.93$ in children nebulized with salbutamol with Ipratropium bromide while it was $69.53 \pm 19.87$ with salbutamol alone. ${ }^{9}$ In this study heart rate/ min was $119.43 \pm 17.09$ versus
$115.3 \pm 18.7$, respiratory rate/min27.9 \pm 4.67 versus 28.97 \pm 5.84 , accessory muscle score was $0.17 \pm 0.46$ versus $0.43 \pm 0.82$ and $\mathrm{SPO}_{2}$ was $96.97 \pm 2.08$ versus $96.4 \pm 1.69$ in Salbutamol with ipratropium group and Salbutamol alone respectively. ${ }^{9}$

\section{CONCLUSION}

Our study results have shown that nebulization of salbutamol in combination with Ipratropium Bromide is more effective in the management of children with acute asthma. It was safe, effective and reliable as there was no adverse side effect noted in our study. We recommend the use of this combination nebulization therapy in children with acute asthma for better outcomes.

\section{Copyright $\odot 07$ May, 2019.}

\section{REFERENCES}

1. Ortiz-Alvarez $O$, Mikrogianakis A. Managing the paediatric patient with an acute asthma exacerbation. Paediatr Child Health. 2012; 17:251-5.

2. Bloomberg FR. The exacerbation component of impairment and risk in pediatric asthma. CUrr Opin Allergy Clin Immunol. 2010; 10(2):155-60.

3. Cheng A; Canadian Paediatric Society, acute care committee. Emergency treatment of anaphylaxis in infants and children. Paediatr Child Health. 2011; 16(1):35-40.

4. Kovesi T, Schuh S, Spier S, Berube D, Carr S, Watson $\mathrm{W}$, et al. Achieving control of asthma in preschoolers. Can Med Assoc J. 2010; 182(4):E172-83.

5. Shoukat S, Gowani SA, Khowaja AA, Khan JA. Assessment of asthma control using asthma control test at a Tertiary Care Centre in Karachi, Pakistan. J Pak Med Assoc. 2009; 59(3):173-6.

6. Hossain AS, Barua UK, Roy GC, Sutradhar SR, Rahman I, Rahman G. Comparison of salbutamol and ipratropium bromide versus salbutamol alone in the treatment of acute severe asthma. Mymensingh Med J. 2013; 22(2):345-52.

7. Griffiths B, Ducharme FM. Combined inhaled anticholinergics and short-acting beta2-agonists for initial treatment of acute asthma in children. Cochrane Database Syst Rev. 2013; 8:CD000060. 
8. Teoh L, Cates CJ, Hurwitz M, Acworth JP, van Asperen P, Chang $A B$. Anticholinergic therapy for acute asthma in children. Cochrane Database Syst Rev. 2012; 4:CD003797.

9. Chakarborti A, Lodha R, Pandey RM, Kabra SK. Randomized controlled trial of Ipratropium Bromide and Salbutamol versus Salbutamol alone in children with acute exacerbation of Asthma. Indian J Pediatr. 2006; 73:979-83.

10. $\mathrm{Al}-\mathrm{Varez} \mathrm{OO}$, Mikrogianakis A. Managing the pediatric patients with acute asthma exacerbations. Paediatr Child Health. 2012 May; 17(5):251-56.
11. Al-Abdullah NO, Al Naama LM, Hassan MK. Antioxidant status in acute asthmatic attack in children. J Pak Med Assoc. 2010; 71(12):1023-7.

12. Memon BN, Parkash A, Mahmood K, Khan A, Ali MGowa, Bai C. Response to nebulized salbutamol versus combination with ipratropium bromide in children with acute severe asthma. J Pak Med Assoc. 2016; 66(3):243-6.

13. Fayaz M, Sultan A, Rai ME. Comparison between efficacy of mdi+spacer and nebuliser in the management of acute asthma in children. $J$ Ayub Med Coll Abottabad. 2009; 21(1):32-4.

\begin{tabular}{|c|c|c|c|}
\hline \multicolumn{4}{|c|}{ AUTHORSHIP AND CONTRIBUTION DECLARATION } \\
\hline Sr. \# & Author(s) Full Name & Contribution to the paper & Author(s) Signature \\
\hline 1 & $\begin{array}{l}\text { Saima Jabeen Joiya } \\
\text { Farhan ul Haq }\end{array}$ & $\begin{array}{l}\text { Methodology, Data collection, } \\
\text { Review of literature. } \\
\text { Data collection. }\end{array}$ & +2 \\
\hline 3 & Muhammad Azam Khan & $\begin{array}{l}\text { Supervision, Methodology, } \\
\text { Discussion. }\end{array}$ & t \\
\hline 4 & Zahid Ahmad & Data analysis, Drafting. & 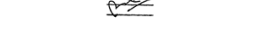 \\
\hline
\end{tabular}

